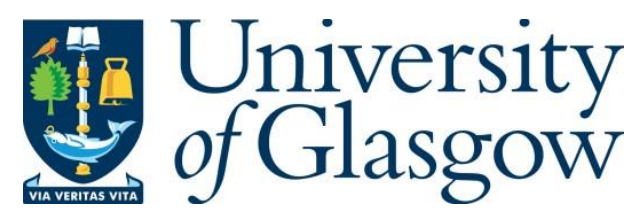

Sashidharan, S.P. and Saraceno, B. (2017) Is psychiatry becoming more coercive? British Medical Journal, 357, j2904.

There may be differences between this version and the published version. You are advised to consult the publisher's version if you wish to cite from it.

http://eprints.gla.ac.uk/143486/

Deposited on: 6 July 2017

Enlighten - Research publications by members of the University of Glasgow http://eprints.gla.ac.uk 


\title{
Is psychiatry becoming more coercive?
}

\author{
S P Sashidharan ${ }^{1}$ Institute of Health and Wellbeing, University of Glasgow, UK \\ Benedetto Saraceno ${ }^{2}$ Institute of Global Mental Health, Lisbon, Portugal
}

The rising trend is damaging for patients, unsupported by evidence, and must be reversed.

Coercion in its various guises has always been central to psychiatry, a legacy of its institutional origins. In the 1970s and 80 s use of coercion in psychiatry fell as old asylums were closed across much of western Europe and replaced with community based care. The focus shifted towards care rather than custody. Recent developments, however, indicate that this balance is shifting again in favour of coercive care, even within well resourced mental health systems. The term coercion has a broad definition in mental healthcare, ${ }^{1}$ but here we focus on the use of force or compulsion.

More and more people are being subjected to coercive psychiatric interventions. In England, the rate of involuntary psychiatric hospital admission has increased by more than a third in the past six years.1 In Scotland, the number of detentions has increased by $19 \%$ in the past five years. ${ }^{2}$ More than half of admissions to psychiatric hospitals in England are now involuntary, the highest rate recorded since the 1983 Mental Health Act.1 The use of coercion in mental healthcare is a global phenomenon. As well as involuntary admission, coercive measures include forced administration of medication, involuntary confinement in isolation or seclusion, and manual or mechanical restraint. ${ }^{3}$

The increasingly coercive culture in mental healthcare is also evident from a renewed trend towards institutionalisation of mentally ill people. ${ }^{4}$ The marked expansion of "protected" housing (secure housing, with restricted freedoms) for people with mental illness in the community and increase in the number of forensic psychiatric beds in many European countries are indicative of this trend. ${ }^{5}$ New types of secure mental health facilities are also emerging, replicating some of the functions of old style asylums. In Italy, for example, a new law in 2012 required the development of secure residential facilities for people with mental disorders considered "socially dangerous." Legislation such as this, disguised as innovation, represents a backwards step. ${ }^{6}$ Our prisons are also increasingly used to manage and contain mentally ill people. There are now over three times more mentally ill people in jails and prisons in the US than in hospitals, and $16 \%$ of them have serious mental illness. ${ }^{7}$ In the UK, $15-25 \%$ of the prison population reportedly has a psychotic illness. ${ }^{8}$

More generally, psychiatric practice, even in seemingly unrestrictive settings, is undergoing a cultural shift towards greater coercion. This is shown by the advent of compulsory treatment in outpatient settings and in the community. Community treatment orders are now "a feature of most developed mental health services, ${ }^{\prime 9}$ although there is little evidence that they offer any benefit. ${ }^{10}$ The use of such orders in England has increased every year since their introduction in 2008. ${ }^{11}$

In its election manifesto, the UK's new conservative government pledged to replace existing mental health legislation in England and Wales with "new laws designed to halt a steep rise in the number of people being detained." It is not yet clear whether the changes will be implemented, but the commitment alone is a belated recognition that the current Mental Health Act has "allowed the 
unnecessary detention of thousands of people and failed to deal with discrimination against ethnic minority patients." ${ }^{\prime 2}$

Risk management has become a central tenet in the care of mentally ill people. Clinical practice seems no longer driven by the needs of the individual but by risk assessments, often of dubious validity. ${ }^{13}$

Psychiatric facilities are increasingly relied upon, instead of prisons, for long term detention of people who have committed sexual or other violent crimes. For example, use in England of the controversial diagnosis "dangerous and severe personality disorder" to detain people in psychiatric hospitals because of their perceived risks to others is an ill conceived attempt to hide preventive detention behind the veneer of respectability provided by a mental health context. ${ }^{14}$

In the US, so called sexual predator laws ${ }^{15}$ allow serious sexual offenders to be detained indefinitely in mental health treatment facilities after they complete prison terms. Although society has the right to be protected, using healthcare facilities to detain people for punishment rather than treatment, is inconsistent with basic medical ethics.

This cultural shift in psychiatry, which prioritises risk management over individual health and social needs is likely to be counterproductive. The stigma associated with mental illness will increase as care becomes more coercive. Further social exclusion of people with mental illnesses is inevitable if we continue to conflate the concept of dangerousness with poor mental health. Those who might benefit from psychiatric care are likely to delay or avoid contact with health services for fear of losing their liberty and compromising their basic rights.

Collaborative and person centred care leading to recovery is an aspiration of most modern mental health services. This aspiration is entirely inconsistent with the increase in compulsion and involuntary care across much of psychiatry. Coercive measures lack supporting evidence and damage patient care. As three commentators recently concluded, "It would be more humane, just and effective to implement alternatives that serve to reduce experienced and actual coercion, promote the wider involvement of people in their care, and potentially improve outcome." ${ }^{16}$

\section{Footnotes}

Competing interests: We have read and understood BMJ policy on declaration of interests and declare SPS is a board member (non-executive) of the Mental Welfare Commission for Scotland.

\section{References}

1 Care Quality Commission. Monitoring the Mental Health Act in 2015/16. http://www.cqc. org.uk/content/monitoring-mental-health-act-report.

2 Mental Welfare Commission for Scotland. Statistical monitoring: Mental Health Act monitoring 2015-16. http://www.mwcscot.org.uk/media/342871/mental_health_act_monitoring_2015-16.pdf

3 McLaughlin P, Giacco D, Priebe S. Use of coercive measures during involuntary admission and treatment outcomes. Data from a prospective study across 10 European countries. PLoS One 2016;357:e0168720.. doi:10.1371/journal.pone.0168720 pmid:28033391. 
4 Priebe S, Turner T. Reinstitutionalisation in mental health care. BMJ 2003;357:175-6. doi: 10.1136/bmj.326.7382.175 pmid:12543817.

5 Priebe $S$, Frottier $P$, Gaddini A, et al. Mental health care institutions in nine European countries, 2002 to 2006. Psychiatr Serv 2008;357:570-3. doi:10.1176/ps.2008.59.5. 570 pmid:18451020.

6 Barbui C, Saraceno B. Closing forensic psychiatric hospitals in Italy: a new revolution begins?Br J Psychiatry 2015;357:445-6.. doi:10.1192/bjp.bp.114.153817 pmid:26034177.

7 Torrey F, Kennrad AD, Eslinger SD, Lamb R, Pavel J. More mentally ill persons are in jails and prisons than in hospitals: a survey of the states. 2010. http://www.

treatmentadvocacycenter.org/storage/documents/final_jails_v_hospitals_study.pdf

8 Prison Reform Trust. Prison; the facts. Bromley Briefings Summer 2016. http://www. prisonreformtrust.org.uk/Portals/0/Documents/Bromley\%20Briefings/summer\%202016\% 20briefing.pdf

9 Burns T. Compulsion in community mental health care: historical developments and current provisions. In: Molodynski A, Rugkasa J, Burns T, eds. Coercion in community mental health careinternational perspectives. Oxford University Press, 2016: 13-22.

10 Kisely SR, Campbell LA. Compulsory community and involuntary outpatient treatment for people with severe mental disorders. Cochrane Database Syst Rev 2014;12:CD004408. doi:10.1002/14651858.CD004408.pub4. pmid:25474592.

11 Care Quality Commission. Monitoring the Mental Health Act in 2012/13. CQC, 2014.

12 Savage M. Theresa May pledges mental health revolution will reduce detentions. Guardian 2017 May 7. https://www.theguardian.com/politics/2017/may/07/theresa-may-pledgesmental-healthrevolution-will-reduce-detentions.

13 Undrill G. The risks of risk assessment. Adv Psych Treat 2007;357:291-7. doi:10.1192/ apt.bp.106.003160.

14 Mullen PE. Dangerous and severe personality disorder and in need of treatment. Br J Psychiatry Suppl 2007;357:s3-7. doi:10.1192/bjp.190.5.s3 pmid:17470940.

15 Mental Health America. Position statement 55: confining sexual predators within the mental health system. 2017. http://www.mentalhealthamerica.net/positions/sexualpredators.

16 Molodynski A, Khazaal Y, Callard F. Coerc. 